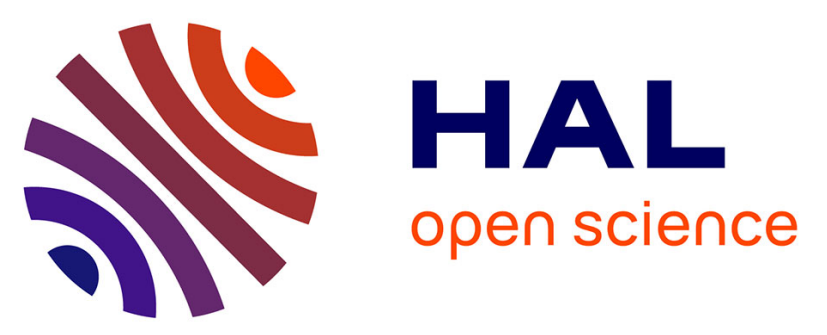

\title{
THE COMPLEMENTARY USE OF ATOM PROBE FIELD ION MICROSCOPY AND ANALYTICAL TRANSMISSION ELECTRON MICROSCOPY FOR THE STUDY OF A Ni-BASE SUPERALLOY
}

\author{
A. Melmed, M. Twigg, R. Klein, M. Kaufman, H. Fraser
}

\section{To cite this version:}

A. Melmed, M. Twigg, R. Klein, M. Kaufman, H. Fraser. THE COMPLEMENTARY USE OF ATOM PROBE FIELD ION MICROSCOPY AND ANALYTICAL TRANSMISSION ELECTRON MICROSCOPY FOR THE STUDY OF A Ni-BASE SUPERALLOY. Journal de Physique Colloques, 1984, 45 (C9), pp.C9-373-C9-378. 10.1051/jphyscol:1984962 . jpa-00224449

HAL Id: jpa-00224449

https://hal.science/jpa-00224449

Submitted on 1 Jan 1984

HAL is a multi-disciplinary open access archive for the deposit and dissemination of scientific research documents, whether they are published or not. The documents may come from teaching and research institutions in France or abroad, or from public or private research centers.
L'archive ouverte pluridisciplinaire HAL, est destinée au dépôt et à la diffusion de documents scientifiques de niveau recherche, publiés ou non, émanant des établissements d'enseignement et de recherche français ou étrangers, des laboratoires publics ou privés. 


\title{
THE COMPLEMENTARY USE OF ATOM PROBE FIELD ION MICROSCOPY AND ANALYTICAL TRANSMISSION ELECTRON MICROSCOPY FOR THE STUDY OF A Ni-BASE SUPERALLOY
}

\author{
A.J. Melmed, M.E. Twigg, R. Klein, M.J. Kaufman ${ }^{*}$ and H.L. Fraser \\ National Bureau of Standards, Gaithersburg, MD 20899, U.S.A. \\ Résumé : Les compositions des phases $\gamma, \gamma^{\prime}$ et $\mathrm{DO}_{22}$ dans le superalliage à base \\ Nickel RSR 143 (76Ni-13A1-9Mo-2Ta, \% at.) ont été déterminées via la microsco- \\ pie ionique à sonde à atomes (APFIM) comme étant 76Ni-6A1-18Mo, 67Ni-25A1-4Mo- \\ $4 \mathrm{Ta}$ et $73 \mathrm{Ni}-4 \mathrm{A1}-20 \mathrm{Mo}-3 \mathrm{Ta}$ respectivement. En utilisant la spectroscopie d'éner- \\ gie dispersive $\mathrm{x}$ en microscopie électronique (TEM), la composition de la phase \\ $\gamma^{\prime}$ (69Ni-22A1-4Mo-5Ta) s'est avérée similaire à celle déterminée par APFIM. \\ L'écart de la composition $\mathrm{DO}_{22}$ par rapport à $\mathrm{Ni}_{3}$ Mo est en accord avec les pré- \\ visions tirées d'une récente étude en TEM (Martin et al, 1980,1982).
}

Abstract: Compositions of the $\gamma, \gamma^{\prime}$ and $\mathrm{DO}_{22}$ phases in the nickel-base superalloy RSR 143 (76Ni-13A1-9Mo-2Ta, at. ${ }^{2}$ ) have been determined via atom probe field-ion microscopy (APFIM) as 76Ni-6A1-18Mo, 67Ni-25A1-4MO-4Ta and be $73 \mathrm{Ni}-4 \mathrm{~A} 1-20 \mathrm{MO}-3 \mathrm{Ta}$ respectively. Using energy dispersive $\mathrm{x}-\mathrm{ray}$ spectroscopy in the analytical transmission electron microscopy (TEM), the composition of the $\gamma^{\prime}$ phase (69Ni-22A1-4Mo-5Ta) was found to be similar to that determined by APFIM. The deviation of the $\mathrm{DO}_{22}$ composition from $\mathrm{Ni}_{3} \mathrm{Mo}$ is in agreement with the prediction of a recent TEM study (Martin et al, 1980, 1982).

At temperatures below $800^{\circ} \mathrm{C}$, RSR $143(76 \mathrm{Ni}-13 \mathrm{~A} 1-9 \mathrm{Mo}-2 \mathrm{Ta}$, at. $\%)$ exhibits a $20 \%$ improvement in stress capability over directionally solidified Mar-M200. Pearson et al. have ascribed this improvement to fine scale secondary precipitates and have recommended the stabilization of these precipitates through compositional modification of the alloy. /1/ Such an objective in alloy design would be more easily accomplished if the composition of the precipitates and the surrounding $\gamma$ matrix were known and if the kinetics for formation and dissolution of such precipitates were understood. The question of kinetics has been addressed in an extensive transmission electron microscopy (TEM) study by Martin et al. $/ 2 / 3 /$. The small size of these secondary precipitates hinders the determination of such compositions through current analytical TEM techniques. The compositions can, however, be determined using atom probe field ion microscopy (APFIM), the principal technique employed in this study.

\section{Experimental}

The heat treatment for RSR 143 chosen for the purpose of this analysis was taken from one of the cases examined by Martin /3/. The sample used here, a slice from a single crystal of RSR 143, was solution treated in vacuum at $1300^{\circ} \mathrm{C}$ for 1 hour and then quenched to ambient temperature. Subsequently, the sample was held at a temperature of $800^{\circ} \mathrm{C}$ for 100 hours. As confirmed by TEM observations, this heat treatment resulted in a large volume fraction of secondary precipitates of the $\mathrm{DO}_{22}$ structure; no precipitates of structures Dla or $\mathrm{Pt}_{2} \mathrm{Mo}$ were observed. The $\mathrm{DO}_{22}$ phase precipitated as platelets on the $\{100\}$ faces of the cuboidal $\gamma$ particles and in the $\gamma$ matrix. The location and morphology of these precipitates can be seen in Figs. $1 \mathrm{a}$ and $1 \mathrm{~b}$.

* Department of Metallurgy, University of Illinois, Urbana, IL. 
The three phases occurring in the RSR 143 crystal subjected to the above heat treatment were found to be easily distinguishable from one another when imaged in the field ion microscope (FIM). From Figs. 2a, 2b, and 2c, we see that the $\mathrm{DO}_{22}$ phase appeared as a bright and very ordered region whereas the $\gamma$ phase appeared as bright but less ordered in FIM specimens imaged in Ne and cooled by $1 \mathrm{iquid} \mathrm{N}_{2}$. In Fig. 2d we see that the $\gamma$ ' cuboids imaged less brightly under the same imaging conditions. The $\gamma^{\prime}$ phase appeared more ordered that the $\gamma$ phase, though less ordered than the $\mathrm{DO}_{22}$ phase.

Microelemental analysis using the APFIM revealed the composition of the $\mathrm{DO}_{22}$ phase as 73Ni-4A1-20Mo-3Ta (at.\%). The composition of the surround $r$ matrix was found to be $76 \mathrm{Ni}-6 \mathrm{~A} 1-18 \mathrm{MO}$. Transmission electron microscopy revealed the size of the $\gamma$ cuboids to be on the order of .5\%; large enough for composition determination by analytical TEM techniques. Using energy dispersive $X$-ray spectroscopy (EDXS), we found the composition of the $\gamma^{\prime}$ to be 69Ni-22A1-4MO-5Ta (at.\%). This composition compared favorably with that obtained using APFIM: 67Ni-25A1-4MO-4Ta. In Table 1, we list the composition for each of the three phases.

\section{Discussion}

It is apparent from the TEM study conducted by Martin /3/ that the DO 22 phase is very stable in RSR 143 held at $800^{\circ} \mathrm{C}$. According to van Tendeloo et al., /4/ however, in an alloy of composition $\mathrm{Ni}_{3} \mathrm{Mo}$, the $\mathrm{DO}_{22}$ phase dissolved in 5 minutes when held at $800^{\circ} \mathrm{C}$. One might suppose then, that additions of $\mathrm{A} 1$ and $\mathrm{Ta}$ play some role in enhancing the stability of the $\mathrm{DO}_{22}$ phase. Because the ordered $\mathrm{DO}_{22}$ is based on the same fcc lattice as the $\gamma^{2}$ precipitates, Martin discussed this role in terms of the statistical theory of long-range order (LRO) developed by de Fontaine $/ 5 /$.

In many theoretical treatments, it is assumed that LRO occurs when an atom of a given species is more strongly attracted to atoms of a different species than to atoms of its own species. One might also guess that the structure of the resulting LRO might be influenced by the relative strength of second nearest neighbor bonds as compared to first nearest neighbor bonds. Indeed, the average pairwise interaction energy existing between ith nearest neighbors is regarded as the fundamental parameter influencing LRO in alloy systems. For a binary alloy system composed of atomic species $A$ and $B$, the average pairwise interaction energy for $i^{\text {th }}$ nearest neighbors is

$$
v_{i}=\frac{1}{2}\left(V_{i}^{A A}+V_{i}^{B B}-2 V_{i}^{A B}\right) \text {. }
$$

Here $v_{i}^{A A}$ and $v_{i}^{B B}$ are the pairwise interaction energies for like $i^{\text {th }}$ nearest neighbors. The term $V_{i}^{A B}$ is the pairwise interaction energy for unlike $i^{\text {th }}$ nearest neighbors. The energies $V_{i}^{A A} v_{i}^{B B}$, and $V_{i}^{A B}$ are negative quantities which become increasingly negative as the bond in question strengthens. In order to favor unlike. $i^{\text {th }}$ nearest neighbors, $v_{i}$ must then be positive.

The significance of the average pairwise interaction energies for first and second nearest neighbors $\left(V_{1}\right.$ and $\left.V_{2}\right)$ in ordering reactions can be seen in terms of their effect on atomic scale composition modulations. The $\mathrm{DO}_{22}$ phase can be described by two sets of standing waves corresponding to composition modulations on an atomic scale: $\left\langle 1 \frac{1}{2} 0\right\rangle$, waves and the $\langle 100\rangle$ waves. The presence of these modulations is obvious from the transmission electron diffraction pattern of the $\mathrm{DO}_{22}$ phase in Fig. 3a. According to de Fontaine, /5/ the $\left\langle 1 \frac{1}{2} 0\right\rangle$ modulation is favored for $\left.0 \mathrm{~S}_{2} / \mathrm{V}_{1}\right\}_{0.5}$. Whereas the $\langle 100\rangle$ modulation is favored for $v_{2} / V_{1} S_{0}$. For both $\left\langle 1 \frac{1}{2} 0\right\rangle$ and $\langle 100\rangle$ modulations, $\left.v_{1}\right\rangle 0$. According to Moss and Ciapp, /6/ x-ray diffraction measurements of spruiell and Stansbury $17 /$ indicate that $\mathrm{v}_{2} / \mathrm{v}_{1}=0.3$ for Ni-Mo alloys. For the same alloy system, Das 
et al., /8/ using transmission electron diffraction, found that $v_{2} / v_{1}=0.4$. One would then presume that the instability of the $\mathrm{DO}_{22}$ phase in the $\mathrm{Ni}_{3} \mathrm{MO}$ alloy was due to a value of $V_{2} / V_{1}$ too large to allow a stable $\langle 100\rangle$ wave to develop.

The $\mathrm{V}_{2} / \mathrm{V}_{1}$ ratio in a $\mathrm{Ni}-\mathrm{Mo}$ alloy could be lowered by adding a small concentration of a third element known to lower $V_{2} / V_{1}$ in another Ni-base alloy system. It is well known that alloy phases of nominal composition $\mathrm{Ni}_{3} \mathrm{Al}^{\text {(such }}$ as the $\gamma^{\prime}$ cuboids in RSR 143) are of the $L_{1} 1_{2}$ structure. As the presence of $\langle 100\rangle$ reflections in the diffraction pattern for the $\gamma^{\prime}$ cuboids in Fig. 3b indicates, 〈100> concentration modulations order the $\mathrm{L}_{2}$ superlattice. In order for the $\langle 100\rangle$ modulation in this phase to exist, however, $v_{2} / v_{1}$ must be less than zero. Therefore, substituting A1 for some of the Mo in the $\mathrm{DO}_{22}$ phase would lower $V_{2} / V_{1}$ and in so doing enhance the stability of the $\langle 100\rangle$ modulation. Because $\mathrm{Ni}_{3} \mathrm{Ta}$ has a high temperature $\mathrm{DO}_{22}$ phase, the addition of $\mathrm{Ta}$ would also be expected to lower $\mathrm{V}_{2} / \mathrm{V}_{1}$ and stabilize the $\langle 100\rangle$ modulation $/ 3 /$. Clearly, these scenarios for stabilizing the $\mathrm{DO}_{22}$ phase are in accord with the observed composition of $73 \mathrm{Ni}-4 \mathrm{~A} 1-20 \mathrm{MO}-3 \mathrm{Ta}$.

\section{References}

1. D. D. Pearson et al., "Factors controlling the creep behavior of a nickel-base superalloy," Creep and Fracture of Engineering Materials and Structures, B. Wilshire and D. R. J. Owen, Eds., Swansea, U. K.: Pineridge Press, 1981, 213-233.

2. P. L. Martin et al., "The structure of as-extruded RSR Ni-A1-Mo and Ni-At-Mo-X alloys," Rapid Solidification Processing Principles and Technologies II, R. Mehrabian et al., Eds., Baton Rouge, La.: Claitors, $1980,123-128$.

3. P. L. Martin, ordering Reactions in Ni-Mo Alloys, Pittsburgh, Pa.: Carnegie-Mellon University (Ph. D. Thesis), 1982.

4. Gustaff van Tedeloo et al., "The $\mathrm{DO}_{22}$ intermediate phase in the $\mathrm{Ni}-\mathrm{Mo}$ system," Phys. Stat. Sol. (a) 20: 457-468, 1975.

5. Didier de Fontaine, "k-Space symmetry rules for order-disorder reactions," Acta Met. 23: 553-571, 1975.

6. S.C. Moss and P. C. Clapp, "Correlation functions of disordered binary alloys III," Phys. Rev. 171: 764-777, 1968.

7. J. E. Spruiel and E. E. Stansbury, "X-ray studies of short-range order in nickel-base alloys containing 10.7 and 20.0 at. $\%$ molybdenum, "J. Phys. Chem. Sol. 26: 811-822, 1965.

8. S. K: Das et al., "Short range order in $\mathrm{Ni}-\mathrm{Mo}, \mathrm{Au}-\mathrm{Cr}, \mathrm{Au}-\mathrm{V}$, and $\mathrm{Au}-\mathrm{Mn}$ alloys," Acta Met. 21: 913-9.28, 1973.

Table 1. Analysis of RSR 143

\begin{tabular}{lllll}
\hline & Ni & A1 & Mo & Ta \\
\hline RSR 143 & 76 & 13 & 9 & 2 \\
\hline DO $_{22}$, APFIM & 73 & 4 & 20 & 3 \\
\hline$\gamma$, APFIM & 76 & 6 & 18 & - \\
\hline$\gamma$, APFIM & 67 & 25 & 4 & 4 \\
\hline$\gamma^{\prime}$, TEM/EDXS & 69 & 22 & 4 & 5 \\
\hline
\end{tabular}


Fig. 1 Transmission electron micrographs of RSR 143.

a) Bright field micrograph. $0.5 \mu$ to $0.1 \mu$ cuboids are $\gamma$ ' precipitates set in the $\gamma$ matrix.

b) Dark field micrograph. Bright, finely dispersed particles set in the $Y$ matrix are $\mathrm{DO}_{22}$ platelets.
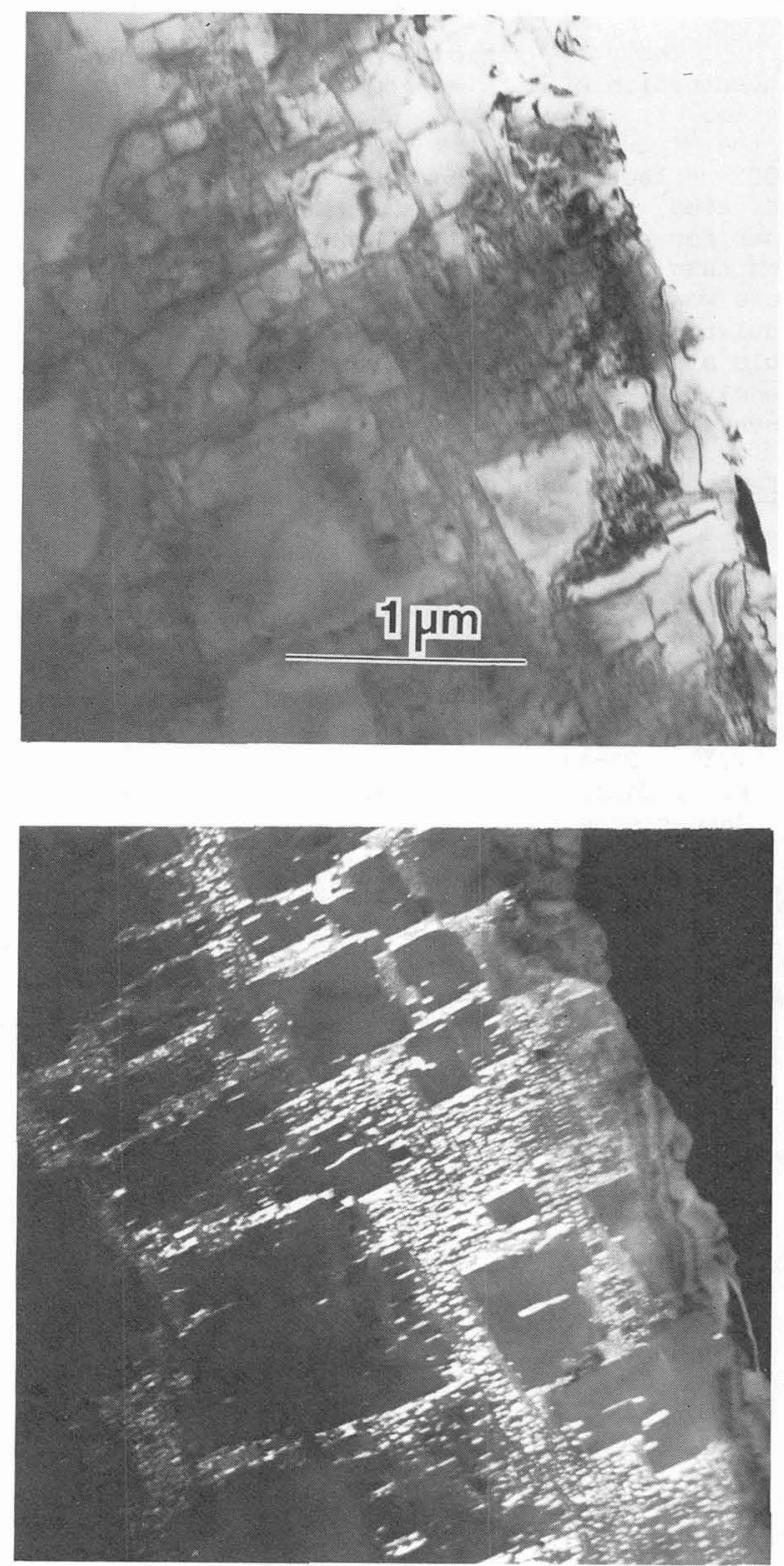
Fig. 2 Field ion micrographs of RSR 143 imaged in Ne at a specimen temperature of $80^{\circ} \mathrm{K}$. a) $\mathrm{Highly}$ ordered $\mathrm{DO}_{22}$ platelet (upper left, diagonally towards center) against background of less ordered $\gamma$ marix. b) $\mathrm{DO}_{22}$ phase. c) $\gamma$ phase. d) $\gamma$ phase. Micrographs b, $c$, and $d$ are of the same magnification.

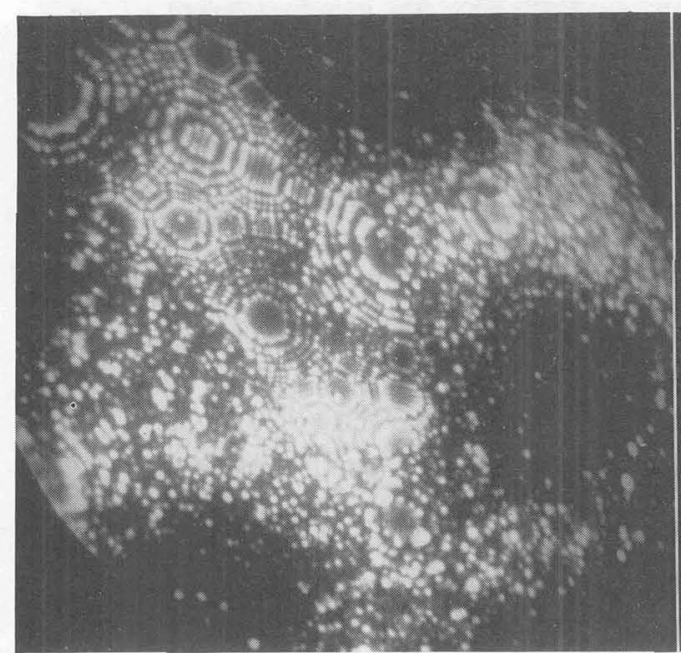

a)

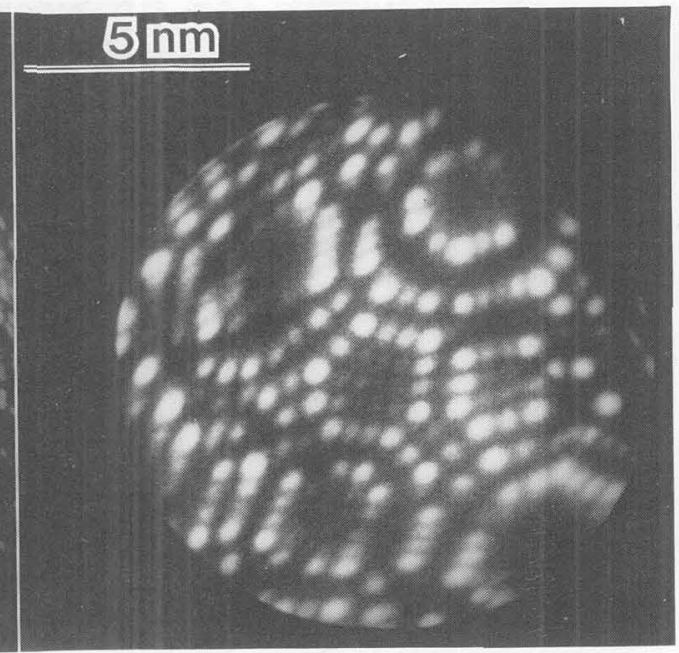

b)

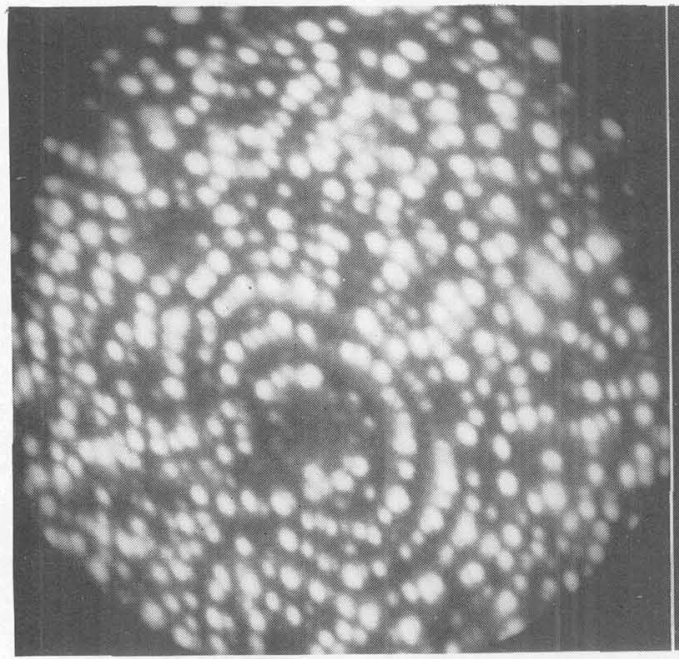

c)

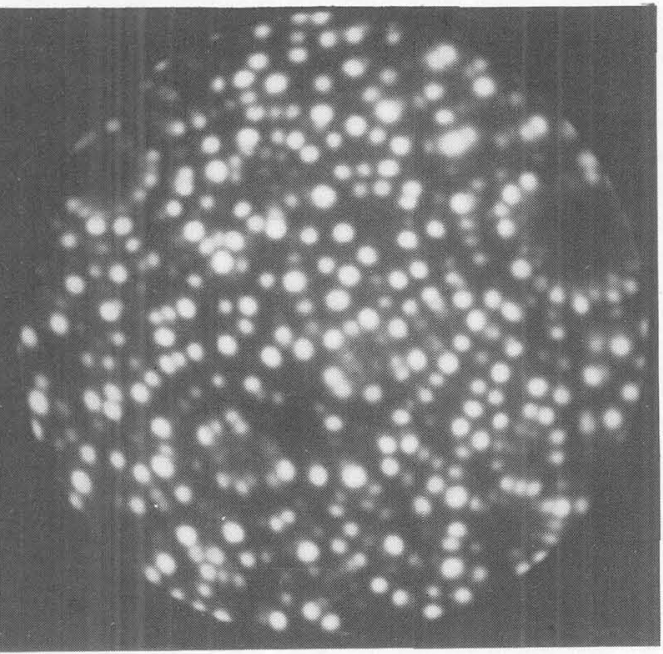

d) 
Fig. 3 Transmission electron diffraction patterns viewed on the [001] zone axis.

a) Selected area diffraction pattern for a region of the $\gamma$ matrix containing $\mathrm{DO}_{22}$ platelets. $\left\langle 1 \frac{1}{2} 0\right\rangle$ and $\langle 100\rangle$ superlattice reflections correspond to composition modulations in the $\left\langle 1 \frac{1}{2}\right\rangle$ and $\langle 100\rangle$ directions.

b) Selected area diffraction pattern for a $\gamma^{\prime}\left(\mathrm{L}_{2}{ }_{2}\right)$ cuboidal precipitate. $\langle 100\rangle$ superlattice reflections correspond to composition modulations in $\langle 100\rangle$ directions.

\section{$\mathrm{DO}_{22}$}

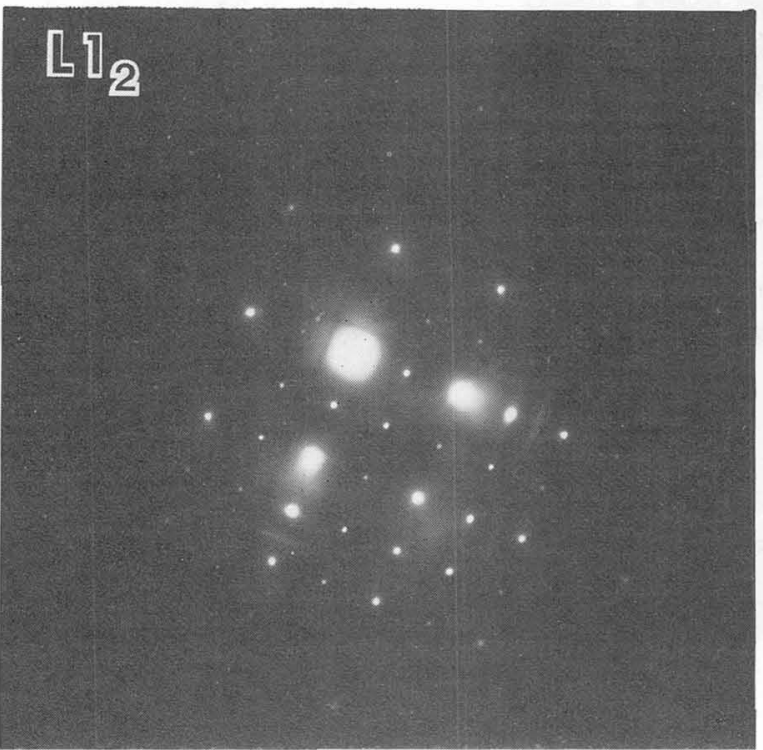

